\title{
Labor market structure and fertility differences among Puerto Rican women: The effects of economic and social policies on opportunity costs
}

\author{
BARBARA A. ZSEMBIK \\ Population Studies Center, University of Michigan, 1225 South University Avenue, \\ Ann Arbor, MI 48104, USA
}

\begin{abstract}
The oft-observed inverse relationship between economic activity in the formal or informal sector and levels of fertility is attributed to the opportunity costs of reproduction. The economic and social policies that initiate and maintain the substantial flow of federal transfer payments to the Puerto Rican population is likely to reduce the opportunity costs among women participating in the informal economy; therefore, informal labor market participants will have fertility levels more like women who have never worked than like women active in the formal labor market. Using data from the 1982 Puerto Rican Fertility and Famly Planning Assessment, this paper compares fertility differentials among ever-married women who have never worked, who have ever worked in the informal economy, and who have only worked in the formal economy. Contrary to expectations, the fertility levels of informal labor market participants are more like those of formal labor market participants; economic activity in either sector is associated with bearing fewer children. Federal transfer payments do not appear to reduce the opportunity costs of reproduction among women employed in the informal economy. An earlier version of this paper was presented at the 1989 meeting of the Population Association of America.
\end{abstract}

In more-industrialized societies, an inverse relationship is most often observed between women's productive and reproductive activities, although in lessindustrialized countries the relationship is not as clear (Conning \& Marckwardt, 1982; Rodriguez \& Cleland, 1981). Several recent studies have suggested that lower levels of fertility may be observed in women who work away from home but that women who work in home industries may not have lower levels of fertility (Chi \& Harris, 1975; Hass, 1971; Jaffe \& Azumi, 1960). Women who work away from home are presumed to experience greater degrees of work and family role incompatibilities, to possess a stronger commitment to the work role, and to have more human capital (e.g., education, work experience and training) than women who work in home industries or women who do not work at all. Standing (1978) suggests that opportunity costs, the underlying mechanism in this neo-classical economic framework, vary by type of labor market structure. Variations in opportunity costs then explain contradictory findings in less-industrialized countries.

This paper argues that opportunity costs do vary by the type of employment 
structure but that their relative effects are conditioned by the structure of social and economic policies. In less-industrialized societies, the opportunity costs of reproduction may be conditioned by policies that affect the form of economic production and the organization of child care. Policies designed to expand women's participation in economic activities are popular among population planners in less-industrialized nations as an indirect route to lower levels of fertility. Consequently, opportunity costs will increase and family size will decrease as more jobs in the productive industrial sectors are created and opened to women. But social welfare policies designed to improve the standard of living among societies' most disadvantaged persons may derail policies enacted directly to increase productive activities and indirectly to contain reproductive activities. Social welfare policies will not influence the relationship between economic activity and the opportunity costs of childbearing for women who have more professional, well-paying jobs. Social welfare policies will, however, attenuate the relationship between economic activity and opportunity costs for women who have low-paying, dead-end jobs. Thus, opportunity costs for women in the secondary labor market may not be high enough to inhibit reproduction.

The aim of this paper is to set a context in which social and economic policies may arguably influence the relationship between the structure of economic activity and levels of reproductive activities among ever-married Puerto Rican women by adjusting the opportunity costs of reproduction. Opportunity costs are assumed to be a function of the interrelatedness of economic growth and development, the distribution of income, governmental transfer programs, and labor market structure. Policies in Puerto Rico have reduced the opportunities and the need for informal labor market activity among women. Specifically, economic and social policies than bind the island to the federal government of the United States most strongly affect the opportunity costs of reproduction.

The concept of opportunity costs has its origins in an article by the economist Jacob Mincer (1963), wherein opportunity costs are viewed as part of the price of children. The opportunity costs of reproduction have long been assumed to determine completed family size (Cramer, 1979; Mason \& Palan, 1981; Mincer, 1963; Smith-Lovin \& Tickamyer, 1978; Turchi, 1975) and are measured as the wages a woman could have earned had she not foregone market activity in favor of domestic life. Opportunity costs reflect structural determinants such as the segmentation of work opportunities along lines of gender, race/ethnicity and class (Bean \& Swicegood, 1985; Beck, Horan \& Tolbert, 1978, 1980; Cochrane, 1979; Doeringer \& Piore, 1979; Gordon, 1972) as well as levels of human capital. But in less-industrialized societies, the structure of economic activity in the informal economy may not be associated with sufficiently high opportunity costs to cause an inverse relationship with fertility to emerge. 
The maternal role incompatibility hypothesis complements the concept of the opportunity costs of children by juxtaposing the differential institutional effects of the organization of production and the organization of child care on the labor supply of women (Mason \& Palan, 1981; Oppong, 1983). Economies that are reliant on women's labor in agricultural or home settings are less likely to engender incompatibilities between productive and reproductive activities. In both industrialized and less-industrialized societies, the organization of child care influences the opportunity costs of productive activity; satisfactory alternatives to maternal-intensive child care will expand the labor supply of mothers. In less-industrialized countries, however, the availability of cheap domestic labor for child care may render the organization of child care relatively compatible with economic activity even in the formal economic setting.

\section{Economic policies}

Economic development policies in Puerto Rico have focused attention primarily on the manufacturing, service and public sectors of the formal economy, while labor opportunities in agriculture, self-employment, and other 'traditional' economic enterprises have been undermined. Operation Bootstrap was a post-World War II series of wage, tax and foreign trade policies designed to supplant a monocrop agricultural economy with an industrial manufacturing economy. The increased global demand for consumer goods (such as small appliances, textiles and garments, electrical and electronic goods) served to expand manufacturing jobs. Concurrently, the economic elite of Puerto Rico capitalized on this growing demand for manufacturing labor by offering tax breaks and shelters and guaranteeing a suitably-skilled, readily-available labor force to manufacturing interests. Consequences of this invited and rapid industrialization included the expansion of employment opportunities for women in the formal economic sector and the contraction of employment opportunities for women in more-traditional industries as well as in the informal economic sector.

The form of the industrialization process in Puerto Rico favoring female employment paradoxically has been facilitated by occupational sex-segregation patterns and declining employment opportunities for men of working age (Pico, 1975; Rivera Quintero, 1979; Zsembik, 1988). Male labor force participation rates have been declining steadily since 1940, cross-cutting all ages. In contrast, female labor force participation rates have been increasing for women between the ages of 18 and 44, especially among women in their $20 \mathrm{~s}$. The consequences of these shifting patterns in labor force participation rates is that gender differentials are diminishing; for example, among men and women aged 20 and $21,65.3$ percent more men than women participated in the 
labor force in 1940, whereas this differential declined to 28.6 percent in 1980 . In 1950, the first date for which employment data are available, 53.6 percent more women than men were not in the labor force, while in 1980 only 25.3 percent more women neither worked nor sought employment. In 1950, 50.8 percent more men than women were employed, but only 22 percent more men than women were employed in 1980 . The fastest-growing occupations are those in which women tend to be concentrated: professional and administrative support and nondurable manufacturing.

Many of the new professional and administrative support positions have occurred in the rapidly expanding governmental sector. The proportion of the employed labor force comprised of government workers has increased since 1950 , especially within the female population. There were 41.2 percent more female government workers in 1980 than in 1950 , whereas there were only 11.9 percent more male government workers in 1980 than in 1950. The importance of government work in the employment experiences of women is illuminated by the small proportionate difference between the 54.1 percent of employed women in private wage and salary jobs and the 42.8 percent of women employed by the federal, commonwealth or municipal government.

The increasing manufacturing sector initially favored the employment of men, but as textiles, electronic and electrical goods and pharmaceuticals dominated the class of material goods produced, manufacturing eventually favored the employment of women. Concomitant with the increasing demand for professional workers (teachers and nurses) and administrative support staff (clerical trades and office workers) and with the relaxation of the sex role norms that heretofore restricted upper-class and middle-class female employment, expanding levels of education have encouraged the gainful employment of middle-class women in white-collar and clerical jobs. Increasingly, lowerclass women have rejected employment opportunities in the garment/textile industry, the expanding service sector industries and the informal sector in favor of these white-collar and pink-collar jobs. As employment opportunities for men in the manufacturing and extractive industries contract and as employment opportunities for women in manufacturing and professional activities expand, it is likely that more women will work than ever before. Indeed, one economist has noted that increasing rates of female labor force participation and declining rates of male labor force participation reflected either the substitution of female for male labor or the 'additional' worker effect. The latter occurs when women work to compensate for declining incomes of their husbands (Dietz, 1986), as seen in female entry into home needlework during the 1930 s and the 1940s.

The effects of variation in labor market structure are likely to be minimized in more-urban, higher-income societies such as Puerto Rico as there are more economic opportunities in the formal economic sector than in the informal 
economic sector. The informal economic sector is thought to arise as a resolution to high levels of poverty and unemployment in rapidly growing urban areas characterized by insufficient employment opportunities in the formal economy. In the face of greater opportunity in the formal economic sector, the size of the informal economic sector may contract. A contracting informal economy can be expected to yield a more homogeneous informal labor force. This more homogeneous composition is more likely to reflect a population trapped in poverty as the more socio-economically mobile informal labor market participants have already moved to positions in the formal economic sector.

\section{Social policies}

The effects of variation in labor market structure also may be minimized when social policies provide economic assistance to the more-disadvantaged members of a society. Specifically, the provision of both cash and noncash benefits attenuates the role that opportunity costs play in the interrelationship between productive and reproductive activity. This effect should be most visible in the unemployed and 'marginally' employed populations, i.e., women and men active in the informal economy. An extensive federal transfer payment system will weaken the inhibitive effect that informal economic activity has on reproductive activities. Social welfare policies reduce the economic need that drives women into the labor force despite domestic demands on their time. Thus social welfare policies may provide an alternative production opportunity structure or household strategy to accumulate resources required for subsistence. The extent to which a society depends upon federal transfer payments will intersect with the extent to which the informal economic sector provides needed employment opportunities to the urban poor.

Federal transfer payments to Puerto Rican islanders have mushroomed in the post-World War II era. As of 1977, more than one-half of the Puerto Rican population received food stamps, although more than 70 percent of the population was eligible for them (United States Department of Commerce, 1979). Of the more than $\$ 2,059$ million distributed in Puerto Rico in 1979,43 percent was in the form of social security payments and 40 percent was in the form of food stamps (Bonilla \& Campos, 1981). 'A third of the value of food sales in 1979 was covered by food stamps. More important, three fourths of those helped by these transfers were among the idle reserves that are the hallmark of modernized Puerto Rico' (Bonilla \& Campos, 1981: 148).

Moreover, the second largest distribution of monies from the United States to Puerto Rico, aside from direct federal transfers, was in the form of 'gifts' to the colonial government to maintain the solvency of the Commonwealth. 
Since World War II, the ranks of public employees has swollen to over 37 percent of all civilian employees. As noted above, women disproportionately have been employed in the expanding governmental sector. In a society where one-fifth of the people are unemployed and three-fifths are poor, federal transfer payments take on great significance in the economic survival of individual families.

Have economic policies in Puerto Rico limited the structure of employment opportunities for women, thereby reducing the opportunity costs of reproductive activity? Do federal transfer payments reduce the costs of bearing additional children for poor Puerto Rican women so that the few employment opportunities in the informal economic sector offer no disincentives for reproduction? In this paper, I will explore these questions by estimating the effects of different types of labor market experience on cumulative levels of fertility. This analysis distinguishes among having no work experience in either labor market, work experience in the informal labor market, and work experience only in the formal labor market. The greater opportunities for middle-class and upper-class women to be employed in the formal labor market and the availability of federal transfer payments to lower-class women is the source of different opportunity costs for Puerto Rican women. Thus, the hypothesis guiding this research is that the fertility levels of informal labor market participants will be similar to those observed in the non-working population as opportunity costs for women in either group are apt to be low. The fertility of formal labor market participants will be lower than that of non-workers and informal labor market participants.

The evidence for evaluating this hypothesis rests on two comparisons: 1) women who have ever worked in the formal market only will be compared both with women who have ever worked in the informal labor market and with women who have never worked in either labor market; and 2) women who have never worked in either labor market will be compared with women who have ever worked in the informal labor market. This will determine whether or not the type of labor market structure is crucial to the understanding of fertility differentials given a context of limited employment opportunities and widespread social welfare coverage.

\section{Data, measures and procedures}

The data used in this research are from the 1982 Puerto Rican Fertility and Family Planning Assessment (PRFFPA), an island-wide, representative sample of never-married and ever-married women between the ages of 15 and $49 .{ }^{1}$ The structure of the Puerto Rican survey is well-suited to the study of the interrelationship between work and family because of the high levels of 
contraceptively-indicated sterilization among women of relatively young ages; this yields a greater proportion of women in several birth cohorts who have completed their childbearing. ${ }^{2}$ Moreover, the availability of detailed employment histories of work in both the formal and the informal sector makes these data unique.

The sample used in this analysis consists of 1,696 ever-married women who were between the ages of 25 and 49 at the time of the interview in 1982 and who had provided complete information on all of the variables used in the analysis. Women who were between the ages of 15 and 24 were omitted to avoid the selectivity bias that occurs with young women who marry earlier and begin childbearing sooner than other women of the same age. The dependent variable in these analysis is the number of children ever born, a measure of cumulative fertility. This measure is most useful as an indicator of completed family size; however, it is biased when used as an estimate of the fertility of younger women who have not yet completed their childbearing career. Restricting the sample to women over the age of 24 (given the high prevalence of sterilization among women over the age of 30 in Puerto Rico) significantly alleviates the major drawback of this measure of fertility.

The independent variable of interest is the type of work history: 1) no work experience at all; 2) work experience in the informal labor market; and 3) work experience only in the formal labor market. The type of work experience was constructed from detailed work histories covering four types of jobs that were held for six months or more since the age of 15 . The first type of job - jobs which paid a wage or salary in cash or in kind - is classified as participation in the formal labor market. The remaining three types of jobs refer to participation in the informal labor market: 1) jobs which reflected business ownership or employment in own business, family business or family farm, whether paid in cash, in kind or not at all; 2) jobs in a home industry or activity which paid in cash or in kind; and 3) jobs which were seasonal in nature and lasted between three and six months for two or more consecutive years. To evaluate informal sector activity, women who have ever worked in the informal labor market are separated from women who have never worked (either in the formal or the informal labor market) and from women who have ever worked only in the formal labor market.

There were 154 ever-married Puerto Rican women in the sample who had never worked in the formal labor market but had worked in the informal labor market, while another 68 women had been labor market participants in both sectors. Women who have worked in both the formal and the informal labor markets are included in the informal labor category; their participation in the formal labor market is as likely to be in as disadvantaged a position as is participation in the informal labor market. Very few women worked as seasonal laborers (6.8 percent), but the number of unpaid family workers was 
considerably greater: 109 of 222 women, or 49.0 percent of all informal labor market participants. The remaining 44.2 percent of informal sector laborers were engaged in economic activity centered in the home. Of the 222 women ever employed in the informal sector, 66.1 percent were employed in the following occupations: sales work, clerical work, dressmaking and private household child care. Sales and clerical workers were concentrated among unpaid family workers; private household child care workers and dressmakers were concentrated among workers in home industries; and the few seasonal workers were employed either as farm laborers or as sales workers. These women were also concentrated in certain industrial sectors -32.7 percent of the informal labor market participants were in either the extractive industries or the retail trade sector.

Cumulative levels of fertility and market experience often are accrued simultaneously, thereby confounding the causal ordering of productive and reproductive events. Women may work only before and/or after their childbearing career or may work concurrently with childbearing. Women who work and bear and raise children simultaneously tend to bear fewer children and to spend more time in productive activity. Although this paper is not directly concerned with the sequencing of productive and reproductive events, the effect of jointly occurring careers must be incorporated. Women who worked over the same time period in which they bore their children are differentiated from women who worked only before and/or after completing childbearing or did not work at all. See Tables 1 and 2 for means, standard deviations and correlations of the variables in the analyses.

Chronological age is included in the analysis as fertility is an age-graded phenomenon, following both biological and social schedules. Education, which determines social status, female work incentives and female employment opportunities (to some degree), is measured as the number of years of school attended. Marital duration is the amount of time in years spent in the married state (including consensual unions), summed over all marriages if a women has been married more than once. Marital duration reflects the amount of time exposed to the risk of pregnancy. The number of marriages, including the current marriage, is the number of legal and consensual relationships. Rural life not only is associated with higher levels of fertility but also is associated with limited opportunities for female employment in the formal sector. Unemployment tends to be high in rural areas, which do not have an active informal sector to absorb surplus female labor. Observations were coded 1 if the respondent resided in a rural area at age 15 and 0 if otherwise. Women residing in rural areas at age 15 are more likely to marry and begin childbearing earlier than women living in more urban areas at age 15 . These rural women generally come from large families of orientation, which are associated with the intergenerational transmission of patterns of high fertility. 
Concomitant with an earlier transition into parenthood, limited employment opportunities further constrain the labor force participation of rural women.

As social class is presumed to distinguish among women prompted into labor market activity according to household economic conditions, a measure of family income as well as that portion of family income derived from the husband's contribution would estimate the effects of financial pressures on the wife to seek employment. There is no measure of income available in these data; husband's occupational prestige is therefore used to identify family financial circumstances, no matter how poorly it does so. Husband's occupational prestige, derived from three-digit occupational codes from the 1980 census according to the NORC rating system, is expected to vary inversely with the number of children ever born, yet also vary positively with the likelihood of wives' employment. This will be especially true among upperand middle-class couples, wherein wives are employed in more prestigious occupations.

Given the relative ease of mobility between Puerto Rico and the mainland of the United States, specifically New York, and given the strongly encouraged emigration of Puerto Ricans to the United States in the 1940s and the 1950s (Morales, 1986), migration experience may serve to suppress cumulative fertility levels. During the same time period there were substantial rural-tourban migration streams which were continually expanding urban areas. Generally, migration is associated with both entry into a social context wherein lower fertility norms are supported and economic opportunities are richer.

Regression results ${ }^{3}$ are presented in Table 3. Panel A compares informal labor market participants and non-workers with formal labor market participants. Panel B compares non-workers with informal labor market participants.

Table 1. Characteristics of sample: ever-married Puerto Rican women, 25-49, 1982.

\begin{tabular}{lccc}
\hline & Percentage & Mean & Standard deviation \\
\hline Number of children ever born & & 2.89 & 1.85 \\
Never worked in either sector & 21.5 & & \\
Ever worked in informal sector & 13.4 & & \\
Ever worked in formal sector & 65.1 & & \\
Worked during childbearing & 18.9 & 37.00 & 7.00 \\
Age & & 10.54 & 4.31 \\
Education (years of school attended) & & 14.13 & 7.39 \\
Marital duration (years) & & 1.23 & 0.52 \\
Number of marriages & 52.3 & & \\
Rural residence at age 15 & & 37.78 & 14.58 \\
Husband's occupational prestige (9-82) & 38.0 & & \\
Ever migrated & & & \\
$\mathrm{N}=1,696$ & & & \\
\hline
\end{tabular}


142

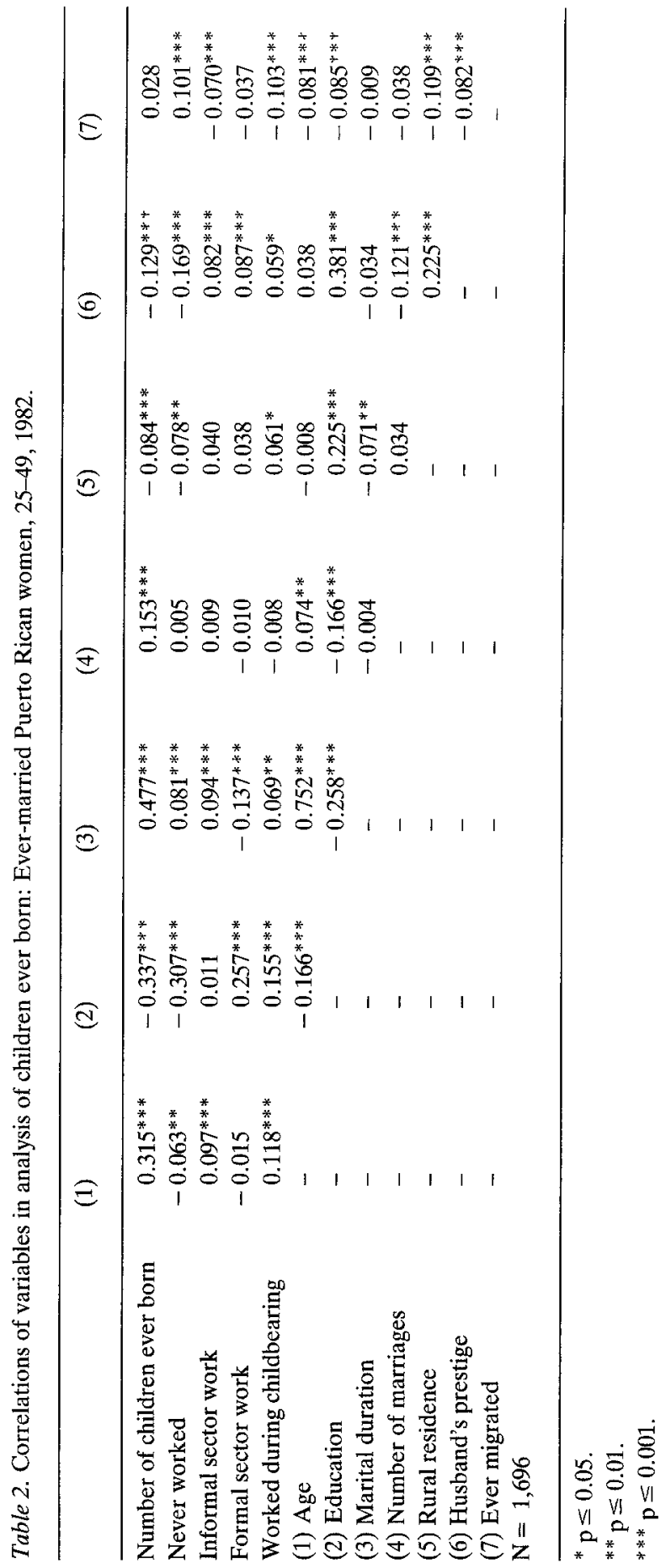




\section{Results}

As panel A shows, there are no differences in fertility levels with regard to type of labor market experience. Women who have ever worked in the informal labor market have fertility levels more like women who have only worked in the formal labor market than like women who have never worked. Women who have never worked in either the formal or the informal labor market have, on average, two-thirds more of a child than other women, even when their estimated fertility levels are adjusted for the effects of other variables. Also contrary to expectation, informal labor market participants have significantly lower levels of fertility than women who have never worked in either labor market (see Panel B). Wives who have never worked have, on average, three-quarters more of a child than women who have ever worked in the informal labor market. Again, this is net of the effects of the control variables.

Women who work during their childbearing career are not significantly different from women who either do not work at all or do not work during the childbearing years. In analyses not presented here a different encoding of the joint career of childbearing and work was not tolerated by the computer procedure. In those analyses women who worked during their childbearing years and women who worked only before and/or after their childbearing years were differentiated from each other and from women who had never worked. This is not to say that the simultaneity of productive and reproductive careers is of little consequence in the lives of Puerto Rican women but, rather, is an indication of the complexity caused by interlocking career trajectories. Indeed, such a phenomenon demands its own exclusive focus. Another study suggests that Puerto Rican women who work during childbearing are not significantly different from women who work only before or only after childbearing (Zsembik, 1989).

Age is negatively associated with the number of children ever born in the first panel but does not gain significance in the second panel. This finding is rather puzzling as the descriptive statistics for each panel suggest that there are no real differences between the samples with regard to age. One possible explanation for this finding and the absence of a significant impact observed in panel $\mathrm{B}$ is that there is sample heterogeneity. Younger women may be more homogeneous with regard to fertility, fecundity, and nuptiality. The cohort of younger women has not yet been diluted by women who marry at later ages and/or voluntarily remain childless. As well, the effects of infertility and subfecundity will become increasingly visible as the younger birth cohort ages but are not yet apparent. Conversely, women who are in the older birth cohorts include both women who married early and bore many children and women who married late and bore few or no children. The effects of agedependent infertility and subfecundity may be observed, in conjunction with the fact that older women are more likely to be surgically sterilized at the end 
Table 3. Unstandardized regression coefficients predicting the mean number of children ever born to ever-marred Puerto Rican women by type of economic activity: 1982

A

Comparison of formal sector workers with informal sector workers and non-workers

\begin{tabular}{lccr}
\hline & $\begin{array}{l}\text { Regression } \\
\text { coefficient }\end{array}$ & $\begin{array}{l}\text { Standard } \\
\text { error }\end{array}$ & t-ratio \\
\hline Never worked in either sector & $0.657^{* * *}$ & 0.103 & 6.380 \\
Ever worked in informal sector & -0.105 & 0.119 & -0.883 \\
Ever worked in formal sector & & & \\
Age & $-0.018^{*}$ & 0.009 & -2.103 \\
Education & $-0066^{* * *}$ & 0.011 & -6.300 \\
Marital duration & $0.121^{* * *}$ & 0.008 & 14.636 \\
Number of marriages & $0.451^{* * *}$ & 0.074 & 6.133 \\
Rural residence at age 15 & -0.036 & 0.079 & -0.454 \\
Husband's occupational prestige & -0.002 & 0.003 & -0.559 \\
Ever migrated (1=yes) & 0.027 & 0.079 & 0.336 \\
Worked during childbearing $(1=$ yes $)$ & 0.037 & 0.106 & 0.353 \\
Constant term & $1.932^{* * *}$ & 0.297 & 6.516 \\
$\mathrm{~F}$ & $77.971^{* * *}$ & & \\
Adjusted $\mathrm{R}^{2}$ & 0.312 & & \\
$\mathrm{~N}=1,696$ & & & \\
\hline $\mathrm{B}$ & & & \\
\hline
\end{tabular}

B

Comparison of non-workers with informal sector workers

\begin{tabular}{lccr}
\hline & $\begin{array}{l}\text { Regression } \\
\text { coefficient }\end{array}$ & $\begin{array}{l}\text { Standard } \\
\text { error }\end{array}$ & t-ratio \\
\hline Never worked in either sector & & & \\
Ever worked in informal sector & $-0.777^{* * *}$ & 0.176 & -4.406 \\
Age & -0.004 & 0.018 & -0.233 \\
Education & $-0.095^{* * *}$ & 0.021 & -4.405 \\
Marital duration & $0.143^{* * *}$ & 0.017 & 8.338 \\
Number of marriages & $0.345^{*}$ & 0.142 & 2.426 \\
Rural residence at age 15 & 0.123 & 0.167 & 0736 \\
Husband's occupational prestige & 0.005 & 0.006 & 0.687 \\
Ever migrated (1 = yes) & 0.112 & 0.164 & 0.798 \\
Worked during childbearing $(1=$ yes $)$ & -1.051 & 1.526 & -0.689 \\
Constant term & $1.795^{* *}$ & 0.578 & 3.106 \\
F & $30.186^{* * *}$ & & \\
Adjusted $R^{2}$ & 0.308 & & \\
N $=592$ & & & \\
\hline
\end{tabular}

${ }^{a}$ Indicates referent group.

${ }^{*} \mathrm{p} \leq 0.05 ;{ }^{* *} \mathrm{p} \leq 0.01 ;{ }^{* * *} \mathrm{p} \leq 0.01$ 
of their childbearing career than are younger women. (See Warren et al., 1986, for age differences in contraceptive prevalence among Puerto Rican women).

Higher levels of education are consistently associated with fewer children ever born. This evidence is consistent with many studies of fertility although the precise mechanisms of the relationship remain unclear (Cochrane, 1979). Also consistent with other fertility studies is the positive association of marital duration and the number of marriages with the number of children ever born. None of the remaining variables - rural residence at age 15, migration experience, and husbands' occupational prestige - achieve significance although the zero-order correlations suggest that each of these indicators is significantly related to the number of children ever born. Urban residence and a lower ranking of the husband's occupation on the prestige scale are not only associated with a higher level of fertility, but also are associated with the likelihood of a woman never working in either labor market. The multivariate analyses indicate, however, that husband's occupational prestige is not associated with a woman's childbearing. It appears that this may be a poor measure of social class. Given the likelihood of migration, rural residence at age 15 seems less important than, say, rural residence during the reproductive years. Women who have never migrated are also more likely to have never worked in either economic sector. These results may be biased towards non-significant coefficients as migrants to the United States at the time of data collection are not surveyed. The ideal comparison would be between migrants to the U.S. who remained on the mainland with women who returned to Puerto Rican and women who never moved to the U.S. Again, it seems that the type of labor market experience is interrelated with a host of other variables in a complex fashion and would be a fruitful area for additional research.

\section{Conclusions}

This research proposed that social welfare policies attenuate the relationship between economic activity and opportunity costs of childbearing for women who work in the informal labor market. Consequently, women who work in the informal labor market may not have fertility levels significantly lower than women who do not work in either the formal or informal labor market. Social welfare policies provide a family with an alternative means to accumulate the resources necessary for subsistence, which becomes a viable strategy under conditions of limited job formation. Thus, the negative effect of informal labor market participation relative to no participation on cumulative fertility levels suggests that women are not deterred from productive activity by federal transfer payments and economic policies inhibiting job formation. This implies that the expansion of economic opportunity in either the informal or 
formal labor market, but especially in the formal market, will further reduce reproductive activity in the long run. Alternatively, women in the informal labor market may have greater needs despite federal transfer policies. The federal transfers surely help somewhat but may still be insufficient. Accordingly, the observation that informal labor market participation is concomitant with high levels of federal transfer payments indicates that future policy initiatives might consider increasing the benefits or significantly expanding economic opportunity in the formal labor market. Clearly the structure of opportunities demarcates the level of opportunity costs and is amenable to intervention at the national and sub-national levels.

I have concluded that economic activity, whether in the formal or the informal labor market, is inversely related to cumulative fertility levels. Beyond the problems inherent in retrospectively-gathered work histories, it is likely that the strength of this relationship is underemphasized. Informal activity is more prevalent among populations characterized by poverty (Todaro, 1985). The widespread poverty in Puerto Rico suggests that the work histories of the women in these data may not adequately represent wives who may be engaged in informal labor activity over the lifecourse and at earlier stages of industrialization on the island. Oftentimes the distinction between economic and nonecomonic activity is ambiguous, especially in rural areas (Pittin, 1984; Anker, 1983). Moreover, how the question is framed may serve to further mask economic activity, e.g., whether the term 'job', 'work', or 'main activity' is used. The PRFFPA uses the term 'job' but describes to the interviewee in detail the kinds of activities that apply, possibly minimizing the issue in this particular instance.

The degree of economic activity in the informal sector may be disguised by interview bias (Pittin, 1984; Anker, 1983). Interview bias may occur with the interviewer, the respondent herself, and/or the conditions under which the interview takes place. Informal economic activity may be underestimated when the interviewer is a middle- or upper-class male with fixed male, middleclass viewpoints on the nature of productive and reproductive activity. The respondent herself may present middle-class norms in an attempt to hide her family's economic need and/or the minimal financial contribution of her husband's economic activities. As well, the fear of economic reprisals, i.e., taxation and penalties, for not reporting all sources and amounts of income may inhibit the respondent from openly disclosing all income-generating activities. Finally, the context of intimate relationships and the balance of power within them may facilitate the concealment of economic activity from the interviewer. The presence of other adult women and/or men (especially the husband) during the interview may encourage the respondent to answer falsely so that she may maintain control over her hidden economic activities. Consequently, research into women's economic activities needs to use an 
activity-oriented schedule to ensure that women's economic activity is not underestimated and that any sample of economically active women is representative. However, activity-oriented schedules are costly, cumbersome and time-consuming, even in a relatively small population such as the inhabitants of the island of Puerto Rico.

This analysis by no means relieves the ambiguity surrounding the relationship between lifetime fertility and work patterns in less-industrialized countries, but it does present additional evidence for an inverse association between productive and reproductive activities. After World War II at least, productive and reproductive activities appear to have been mutually inhibitive among Puerto Rican women, although the type of labor market is not a significant determinant of fertility differentials. Moreover, social welfare policies in Puerto Rico, although providing substantial income maintenance, do not appear to attenuate the effects of opportunity costs of reproductive activities for women in the informal labor market.

It appears then that economic activity in the informal labor market is an important determinant of the level of fertility among Puerto Rican women. Indeed, economic activity in the informal sector will become more important if federal transfer payments shrink and employment opportunities in the formal labor market contract. As the industries that favor women as workers have more recently relocated to other islands in the Caribbean Basin, they have not been replaced with opportunities for employment in the formal sector. The informal labor market is less likely to be contracting into a homogeneous labor force, given the recent economic crises in Latin America and contracting employment opportunities in the industrial Northeast. Indeed, the informal labor market is likely to be expanding and becoming more heterogeneous as high levels of poverty and unemployment crystallize a permanent underclass.

But an expanding informal economy is an incomplete opportunity structure and cannot serve as the basis of employment opportunities for women or for men. The opportunity structure of economic activity in Puerto Rico is imbalanced towards jobs with little social or economic returns. Although federal transfer payments surely ease the burden of poverty, unemployment and underemployment, it is only a palliative for the effects of a stultified opportunity structure of production. Provision and support are needed for an opportunity structure that allows both men and women the flexibility and opportunity to design the most appropriate strategies to accumulate the necessary resources for survival and for an adequate quality of life. 


\section{Acknowledgments}

I gratefully acknowledge comments by John B. Casterline and an anonymous reviewer on an earlier version of this paper.

\section{Notes}

1. See Presser, 1980 for a complete discription of trends in sterilization among Puerto Rican women in general and Herold et al., 1986 and Warren et al., 1986 for a complete description of sterilization prevalence in these data.

2. The sampling frame was a two-stage disproportionate stratified cluster sample designed to be representative of the entıre island population. Interviews were completed with 3,175 women. See Herold et al., 1986 and Warren et al., 1986 for additional details on the sampling frame.

3. Tests for multicollinearity indicate that it is not a problem in these analyses.

\section{References}

Anker, R. (1983). 'Female labour force participation in developing countries: A critique of current definitions and data collection methods,' International Labour Review 122: 709-723.

Bean, F.D. and G. Swicegood (1985). Mexican Amercan Fertility Patterns. Austin, TX: University of Texas Press.

Beck, E.M., P.M. Horan and C.M. Tolbert II (1978). 'Stratification in a dual economy,' American Sociological Review 43: 704-720.

Beck, E.M., P.M. Horan and C.M. Tolbert II (1980). 'Industrial segmentation and labor market discrimination.' Social Problems 28: 113-130.

Bonilla, F. and R. Campos (1981). 'A wealth of poor: Puerto Ricans in the new economic order,' Daedalus 110: 133-176.

Chi, S.K.P. and R. Harris (1975). 'Interaction between action progammes and social structural variables: A study of family planning and fertility differentıals in four Colombian cities.' Paper presented at the annual meetings of the Population Association of America, Seattle, WA. (As cited in Standing, 1978).

Cochrane, S.H. (1979). Fertility and Education: What Do We Really Know? Baltimore: Johns Hopkins University Press.

Conning, A.M. and M.A. Marckwardt (1982). 'Analysis of WFS data in Columbia, Panama, Paraguay and Peru: Highlights from the CELADE research and training seminar.' WFS Occasional Papers No. 25.

Cramer, J.C. (1979). 'Employment trends of young mothers and the opportunity costs of babies in the United States,' Demography 16: 177-197.

Dietz, J.L. (1986). Economic History of Puerto Rico: Institutional Change and Capitalist Development. Princeton: Princeton University Press.

Doeringer, P.B. and M.J. Piore (1979). Internal Labor Markets and Manpower Analysis. Lexington, MA: Heath.

Gordon, D.M. (1972). Theories of Poverty and Underemployment. Lexington, MA: Heath.

Hass, P.H. (1971). 'Maternal role incompatibility and fertility in urban Latin America,' Journal of Social Issues 28: 111-127.

Herold, J.M., C.W. Warren, J.C. Smith, R.W. Rochat, R. Martinez and M. Vera (1986). 
'Contraceptive use and the need for family planning in Puerto Rico,' Famlly Planning Perspectives 18: 185-190.

Jaffe, A.J and K. Azumi (1960). 'The birthrate and cottage industries in underdeveloped countries', Economic Development and Cultural Change 9: 52-63.

Mason. K.O. and V.T. Palan (1981). 'Female employment and fertlity in Peninsular Malaysia: The maternal role incompatibility hypothesis reconsidered,' Demography 18: 549-575.

Mincer, J. (1963). 'Market prices, opportunity costs, and income effects,' in C. Crist (ed.). Measurement in Economics: Studies in Mathematical Economics and Econometrics in Memory of Yehudsa Grunfeld. Stanford, CA: Stanford University Press.

Morales, J. (1986). Puerto Rican Poverty and Migration. We Just Had to Try Elsewhere. New York: Praeger Publishers.

Oppong, C. (1983). 'Women's roles, opportunity costs, and fertility,' in R. Bulatao and R. Lee (eds.), Determinants of Fertlity in Developing Countries. Volume I. New York: Academic Press.

Pico, I. (1975). 'Estudio sobre el empleo de la mujer en Puerto Rico,' Revista de Ciencias Sociales 19: 141-165.

Pittin, R. (1984). 'Documentation and analysis of invisıble women: A Nigerian case-study,' International Labour Review 123: 473-490.

Presser, H.B. (1980). 'Puerto Rico: Recent trends in fertility and sterilization,' International Family Planning Perspectives 6: 21-25.

Rivera Quintero, M. (1979). 'The development of capitalism in Puerto Rico and the incorporation of women in the labor force,' in E. Acosta-Belen (ed.), The Puerto Rican Woman. 1st Edition. New York: Praeger Publishers.

Rodriguez, G. and J. Cleland (1981). 'Socio-economic determinants of marital fertility in twenty countries: A multivariate analysis,' in World Fertility Survey Conference, 1980: Record of Proceedings 2.

Smith-Lovin, L. and A.R. Tickamyer (1978). 'Nonrecursive models of labor force participation, fertility behavior and sex role attıtudes,' American Sociologıcal Review 43: 541-557.

Standing, G. (1981). Unemployment and Female Labour. A Study of Labour Supply in Kingston, Jamaica. London: Macmillan.

Standıng, G. (1978). Labour Force Participation and Development. Geneva: International Labour Organization.

Todaro, M.P. (1985). Economic Development in the Third World. Third Edition. New York: Longman.

Turchi, B. (1975). The Demand for Children: The Economics of Fertility in the U.S. Cambridge, MA: Ballinger.

United States Department of Commerce. Interagency Study Group. (1979). Economic Study of Puerto Rico. Volume I. Washington, D.C.: U.S. Government Printing Office.

Warren, C.W., C.F Westoff, J.M. Herold, R.W. Rochat and J.C. Smith (1986). 'Contraceptive sterilization in Puerto Rico,' Demography 23: 351-365.

Zsembik, B.A. (1989). 'The temporal sequencing of productive and reproductive activities of Puerto Rican women,' unpublished manuscript.

Zsembik, B.A. (1988). 'The historical circumstances of female labor in Puerto Rico,' unpublished manuscript. 